archives-ouvertes

\title{
Expanding the Synthesis Field of High-Silica Zeolites
}

Diandian Shi, Kok-Giap Haw, Cassandre Kouvatas, Lingxue Tang, Yiying Zhang, Qianrong Fang, Shilun Qiu, Valentin Valtchev

\section{To cite this version:}

Diandian Shi, Kok-Giap Haw, Cassandre Kouvatas, Lingxue Tang, Yiying Zhang, et al.. Expanding the Synthesis Field of High-Silica Zeolites. Angewandte Chemie International Edition, Wiley-VCH Verlag, 2020, 59 (44), pp.19576-19581. 10.1002/anie.202007514 . hal-03040578

HAL Id: hal-03040578

\section{https://hal-normandie-univ.archives-ouvertes.fr/hal-03040578}

Submitted on 4 Dec 2020

HAL is a multi-disciplinary open access archive for the deposit and dissemination of scientific research documents, whether they are published or not. The documents may come from teaching and research institutions in France or abroad, or from public or private research centers.
L'archive ouverte pluridisciplinaire HAL, est destinée au dépôt et à la diffusion de documents scientifiques de niveau recherche, publiés ou non, émanant des établissements d'enseignement et de recherche français ou étrangers, des laboratoires publics ou privés. 


\section{Expanding the synthesis field of high silica zeolites}

3 Diandian Shi, ${ }^{[a]}$ Kok-Giap Haw, ${ }^{[a]}$ Cassandre Kouvatas, ${ }^{[b]}$ Lingxue Tang, ${ }^{[a]}$ Yiying Zhang, ${ }^{[a]}$ Qianrong

4 Fang, ${ }^{[a]}$ Shilun Qiu, ${ }^{[a]}$ Valentin Valtchev ${ }^{*[b, c]}$

6 Abstract: Aluminosilicate zeolites are synthesizeab

7 under hydrothermal conditions in basic/alkalin 7

8 medium in the $p H$ range between 9 and 14. Hers8

9 we report the synthesis of MFI-type zeolite ing

10 acidic medium. The critical paramete 40

11 determining the zeolite formation in acidi 1

12 medium was found to be the isoelectric point2

13 (IEP) of gel particles. MFI-type zeolite wat3

14 synthesized above the isoelectric point of th $\$ 4$

15 employed silica source, where the silica specie\$5

16 exhibit a negative charge and the paradigm of6

17 zeolite formation based on the electrostati 7

18 interaction with the positively charged templat 8

19 retained. No zeolite formation is observed below9

20 the isoelectric point of silica. The impact ofy

21 aluminum on the zeolite formation is also studie 1

22 The results of this study will serve to extend th 2

23 zeolite synthesis field of high silica zeolites to the 3

24 acidic medium and thus open new opportunities t54

25 control the zeolite properties.

\section{Zeolites are microporous aluminosilicat57} molecular sieves that have a variety of significant 8 applications in catalysis, adsorption, separation,9 and ion exchange. ${ }^{[1]}$ The intensive industrial us 60 of zeolites is based on their unique properties a 81 ordered channel systems containing active sites i 62 a well-defined confine environment, which is the3 origin of their unraveled shape-selectivity, an 64 molecular sieving properties. ${ }^{[2]}$

[a] D. Shi, Dr. K.-G. Haw, L. Tang, Y. Zhang, Prof. Q. Fang, Prof. S. Qiu

State Key Laboratory of Inorganic Synthesis and

Preparative Chemistry, Jilin University, Changchun 130012, P. R. China

[b] Prof. V. Valtchev, Dr. C. Kouvatis

Normandie Univ, ENSICAEN, UNICAEN, CNRS,

Laboratoire Catalyse et Spectrochimie, 6 Marechal Juin,

14050 Caen, France

E-mail: valentin.valtchev@ensicaen.fr

[c] Prof. V. Valtchev

Qingdao Institute of Bioenergy and Bioprocess Technology, Chinese Academy of Sciences, 189 Songling Road, Laoshan District, Qingdao, Shandong 266101, P. R. China

Supporting information for this article is available on the WWW under http://www.angewandte.org or from the author.
In general, zeolites are synthesized under hydrothermal conditions in a basic medium where the $\mathrm{OH}^{-}$is the mineralizing agent. The conventional zeolite syntheses are performed at relatively high $\mathrm{pH}(>9)$ using alkali metal and/or tetraalkylammonium cation as a structuredirecting agent (SDA). ${ }^{[3]}$ Zeolites are also synthesized using $\mathrm{F}^{-}$as a mineralizer. The synthesis in fluoride medium is usually performed under neutral conditions $(\mathrm{pH}=6-8) .{ }^{[4]}$ The physicochemical properties of a zeolite obtained by the hydroxide and fluoride route differ substantially. ${ }^{[5]}$ Thus, both routes deserve attention, although the industrial syntheses are limited to the use of the hydroxide medium.

The synthesis in the basic medium was first developed, mimicking the zeolite formation in nature, namely the high-temperature hydrothermal conditions in pegmatites. ${ }^{[6]}$ These syntheses were performed at temperatures higher than $250{ }^{\circ} \mathrm{C}$. In the late 50ies, Milton discovered that zeolites can be obtained under much lower temperatures using highly reactive alkaline aluminosilicate hydrogels. ${ }^{[7]}$ This synthesis mode, which is used in the industry, was further developed by Breck. ${ }^{[8]}$

The fluoride medium synthesis of zeolites, pioneered by Flanigen and Patton in the late 1970s, ${ }^{[9]}$ was an important breakthrough diversifying the synthesis conditions and providing materials with different properties. Guth, Kessler, and co-workers further developed this synthetic route. ${ }^{[10]}$ This group systematically 8 studied the zeolite formation in fluoride medium 9 and synthesized different microporous materials, 0 including aluminosilicates, aluminophosphates, 1 and gallophosphates. The syntheses were 2 performed in the $\mathrm{pH}$ range 5-9, and an attempt to 3 obtain zeolite below $\mathrm{pH}=5$ was reported. ${ }^{[11]}$ 4 However, the formation of zeolite at $\mathrm{pH}$ below 5 5 without using seeds was not achieved.

In the conventional basic/alkaline medium 7 synthesis, the nucleation is abundant, and the 8 crystals grow fast. Consequently, they contain a 9 lot of intergrowths and a relatively large number 
80 of framework defects. ${ }^{[12]}$ Under framework0

81 defects, we refer missing $\mathrm{T}$ (tetrahedral) atoln1

82 replaced by silanols. The presence of defect2

83 silanols has a negative impact on zeolite catalyd 33

84 since it is a coke trap in the hydrocarboh 34

85 conversion. ${ }^{[13]}$ The silanols also decrease tha5

86 hydrophobicity of the all-silica zeolitis 6

87 materials. ${ }^{[14]}$ Similar problems can be reduced td 37

88 considerable extent by the synthesis in fluoritze

89 medium where the crystals grow slowly, whick9

90 limits the number of defects. Bleken et al. showkAl0

91 that the coke formation in ZSM-5 prepared via the1

92 fluoride route is negligible with respect to the 2

93 hydroxide medium prepared counterpart. ${ }^{[15]}$ Thust3

94 the fluoride route has shown its most notablet4

95 advantage in producing zeolite crystals of fewlet5

96 framework defect sites. ${ }^{[16]}$ However, the zeolite6

97 crystals synthesized in fluoride medium alre7

98 usually several tens of micrometers large ah 18

99 impose diffusion limitations, which limits theit9

100 applications. On the other side, the fluorids0

101 medium growth crystals are of great importanceli51

102 fundamental studies of zeolites. From a practida 2

103 point of view, the synthesis in fluoride mediun 53

104 might present interest since the low $\mathrm{pH}$ might b 4

105 appropriate to incorporate transition metals in the5 106 zeolite structure. ${ }^{[17]}$

156

107 The objective of this work is to extend the7

108 zeolite formation at the $\mathrm{pH}$ range below 5, i.es,8

109 under acidic conditions without the assistance 1079

110 seeds. This objective involves fundamental ah60

111 practical aspects since the results of the study with1

112 provide valuable information about the critida2

113 factors controlling zeolite formation and bring3

114 more flexibility in the preparation of zeoliti64

115 materials with controlled properties.

165

116 It is well known that silica source plays an6

117 important role in zeolite synthesis. ${ }^{[18]}$ Using7

118 different silica sources may result in changing the8

119 crystallization pathway and even in the formatib69

120 of an undesired crystalline phase. The preliminary0

121 work on the optimization of gel composition ahd1

122 reaching a successful synthesis of the zeolite waz2

123 performed with pyrogen silica known as fumed3

124 silica. We selected this silica source since it waßn

125 previously used in the fluoride medium synthesis5

126 of zeolites. ${ }^{[10 c]}$ MFI-type zeolite was obtaineđ6

127 from a gel with molar composition $1.0 \mathrm{SiO}_{2}: 0.37$

$128 \mathrm{TPABr}: 0.00167 \mathrm{Al}_{2} \mathrm{O}_{3}$ : x HF : y $\mathrm{NH}_{4} \mathrm{~F}: 40.68$

$129 \mathrm{H}_{2} \mathrm{O}$, where $\mathrm{x}$ and $y$ were varied to control the $\mathrm{pH} .9$
The details on synthesis can be found in the Supporting Information. Using a gel composition with $\mathrm{Si} / \mathrm{Al}=300$, highly crystalline MFI-type material was obtained at $\mathrm{pH}=5.0,3.6$, and 2.3 (Figure 1). The synthesis with a gel with an initial $\mathrm{pH}$ of 2.3 and $\mathrm{Si} / \mathrm{Al}=300$ was reproduced using tetraethylorthosilicate (TEOS), colloidal silica (Ludox AS-40), and silicic acid as silica sources. The $\mathrm{pH}$ of the mother liquor after the synthesis was measured. In all case the $\mathrm{pH}$ was lower than in the initial gel, but varied as a function of silica source. Thus for fumed silica, TEOS, and silicic acid the final $\mathrm{pH}$ was about 1.7 , while for the colloidal silica 1.9. The XRD patterns of the samples synthesized from these silica sources are presented in Figure S1. Thus using fumed silica, TEOS, and Ludox AS-40 yielded pure and highly crystalline MFI-type zeolite. Only traces of MFI were observed in the synthesis with silicic acid. Poor crystallinity of zeolite phase might be due to the relatively large silica particles, which might require much longer synthesis time (Figure S2e,f). Nevertheless, this set of results proved that the crystallization of zeolitic material in acidic medium is possible. The SEM inspection showed that all silica sources yielded MFI-type crystals with the typical coffin morphology (Figure S2). The crystals range between 10 and $50 \mu \mathrm{m}$ in size. Ludox AS-40 synthesized material contains some small particles, most probably amorphous, covering the large zeolite crystals. No traces of amorphous material were observed in the TEOS synthesized sample. The amorphous phase, large particles with random shape, dominated the product obtained with silicic acid. A few but wellshaped crystals with the characteristic of MFItype material features were observed in this sample.

The incorporation of hetero elements in the zeolite framework is indispensable for catalytic applications, which is a major field of zeolite uses. Therefore, the impact of aluminum on the zeolite crystallization in acidic medium was studied. The best result in terms of zeolite crystallinity was obtained with fumed silica. Thus the synthesis of Al-containing MFI-type material was performed with this silica source. The crystal growth kinetics of a gel with $\mathrm{Si} / \mathrm{Al}$ ratio of 300 and relatively low $\mathrm{pH}$ (2.3) was studied and used as a reference for the synthesis duration. The hydrothermal 
180 treatment was performed at $160{ }^{\circ} \mathrm{C}$. The first trace 181 of MFI was observed after four days, and a fully 182 crystalline material obtained after 13 days (Figure 183 S3). This reference synthesis was used to calculate 184 the zeolite yield, which was found to be $78 \%$, 185 based on the silica plus alumina content in the 186 initial gel. Consequently, all experiments related 187 to the impact of aluminum on the zeolite 188 formation under acidic conditions were performed 189 at $160{ }^{\circ} \mathrm{C}$ for 13 days. The initial $\mathrm{pH}$ was 2.3 and 190 the molar composition of the gel was $1.0 \mathrm{SiO}_{2}$ : $1910.3 \mathrm{TPABr}: \mathrm{z} \mathrm{Al}_{2} \mathrm{O}_{3}: 0.36572 \mathrm{HF}: 0.17124$ $192 \mathrm{NH}_{4} \mathrm{~F}: 40.6 \mathrm{H}_{2} \mathrm{O}$, where $\mathrm{z}=0.01,0.005,0.0033$, 1930.00167 , and 0 , giving a $\mathrm{Si} / \mathrm{Al}$ ratio of 50,1080 194150,300 and infinity $(\infty)$. The synthesized 195 samples were denoted FS-50, FS-100, FS-1391 $196 \mathrm{FS}-300$, and FS- $\infty$ as a function of the $\mathrm{Si} / \mathrm{Al}$ ratio. 197 The XRD patterns of the obtained products are 198 depicted in Figure S4 and their relative 203 crystallinity presented in Table 1 . silica as a silica source. gels with silicon to aluminum ratio higher thaß 0 150. The crystallinity of the samples synthesizeal 1 from gels with $\mathrm{Si} / \mathrm{Al}$ ratio of 100 and 50 w 232 lower. A closer look at their XRD patterns reveaß33 the presence of an amorphous phase, i.e., a halozis 4 the $20-30^{\circ}$ Two Theta range, for these tख 25 samples. The extension of the crystallization tim 6 to 18 days improved the crystallinity of FS-1DB7 (Figure S5) and FS-50 (Figure S6); yet some8 amorphous material was present in the solid. The9 SEM inspection confirmed that FS- $\infty$, FS-3028,0 and FS-150 are highly crystalline products (Figute 1 2 ). The crystals are well-shaped with clean facest. 2 No trace of other phase was observed. FS-100 a 413 FS-50 contain crystals with the characteristic 24 MFI-type material morphology. The crystals art5 covered with small particles that do not exhiBit6 crystalline features. The amount of this phaset 7

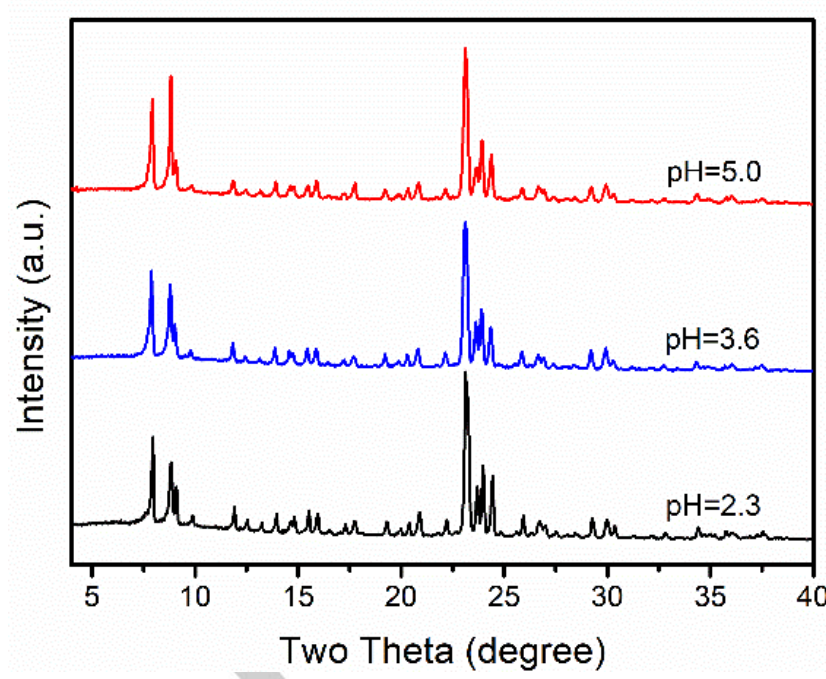

Figure 1. XRD pattern of the MFI-type samples synthesized from gels with different $\mathrm{pH}$ values at $160^{\circ} \mathrm{C}$ for 13 days.

Table 1. Physicochemical characteristics of the MFI-type samples synthesized from gels with $\mathrm{pH}=2.3$ and different $\mathrm{Si} / \mathrm{Al}$ ratios at $160{ }^{\circ} \mathrm{C}$ for 13 days using fumed

\begin{tabular}{|c|c|c|c|c|c|c|c|c|}
\hline \multirow[t]{2}{*}{ Sample } & \multicolumn{2}{|c|}{ Si/Al ratio } & \multirow{2}{*}{$\begin{array}{c}\text { Crystallinity } \\
\text { (\%) }\end{array}$} & \multicolumn{2}{|c|}{ Weight loss (\%) } & \multirow{2}{*}{$\begin{array}{l}\mathrm{S}_{\mathrm{BET}} \\
\mathrm{m}^{2} \mathrm{~g}^{-1}\end{array}$} & \multirow{2}{*}{$\begin{array}{l}V_{\text {micro }} \\
\mathrm{cm}^{3} \mathrm{~g}^{-1}\end{array}$} & \multirow{2}{*}{$\begin{array}{l}V_{\text {total }} \\
\mathrm{cm}^{3} \mathrm{~g}^{-1}\end{array}$} \\
\hline & Initial gel & Crystalline product & & $25-300\left({ }^{\circ} \mathrm{C}\right)$ & $0-600\left({ }^{\circ} \mathrm{C}\right)$ & & & \\
\hline FS- $\infty$ & $\infty$ & $\infty$ & 100 & 0.37 & 12.42 & 336 & 0.18 & 0.18 \\
\hline FS-150 & 150 & 182 & 100 & 0.88 & 12.34 & 466 & 0.18 & 0.18 \\
\hline FS-100 & 100 & 113 & 63 & 1.20 & 7.51 & 253 & 0.11 & 0.14 \\
\hline FS-50 & 50 & 61 & 33 & 3.68 & 5.28 & 128 & 0.05 & 0.12 \\
\hline
\end{tabular}

Highly crystalline samples were obtained using9 of XRD pattern, is larger in the FS-50 sample (Figure S6). The results of the SEM and XRD studies are in good agreement and confirm that a high concentration of $\mathrm{Al}$ is not favorable for the zeolite formation in acidic medium.

The system yielding FS-300 was used to explore the $\mathrm{pH}$ range below 2 as the $\mathrm{NH}_{4} \mathrm{~F}$ was kept constant, and the content of HF was varied to control the $\mathrm{pH}$. The formation of MFI-type zeolite was still possible at $\mathrm{pH}=2$, but the crystallinity of the sample obtained after 13 days of hydrothermal treatment was relatively low. The synthesis was extended to 18 days to get a highly crystalline product (Figure S7). Further decrease of the $\mathrm{pH}$ to 1.5 resulted in amorphous solid after 13 days of hydrothermal treatment. The first traces of MFItype material were observed after 23 days of crystallization (Figure S8), while the solid obtained after 33 days contained MFI-type material and amorphous. The crystallinity of the 
249 zeolite phase was improved after 38 days $25 f 6$ 250 crystallization, but new peaks in the $20-23^{\circ}$ TQ57 251 Theta range appeared in the XRD pattern. Thes 8 252 peaks reveal the co-crystallization of a dense no259 253 zeolitic phase. The synthesis at $\mathrm{pH}=1 \mathrm{did}$ noto 254 yield MFI-type material after 40 days 2661 255 hydrothermal treatment.
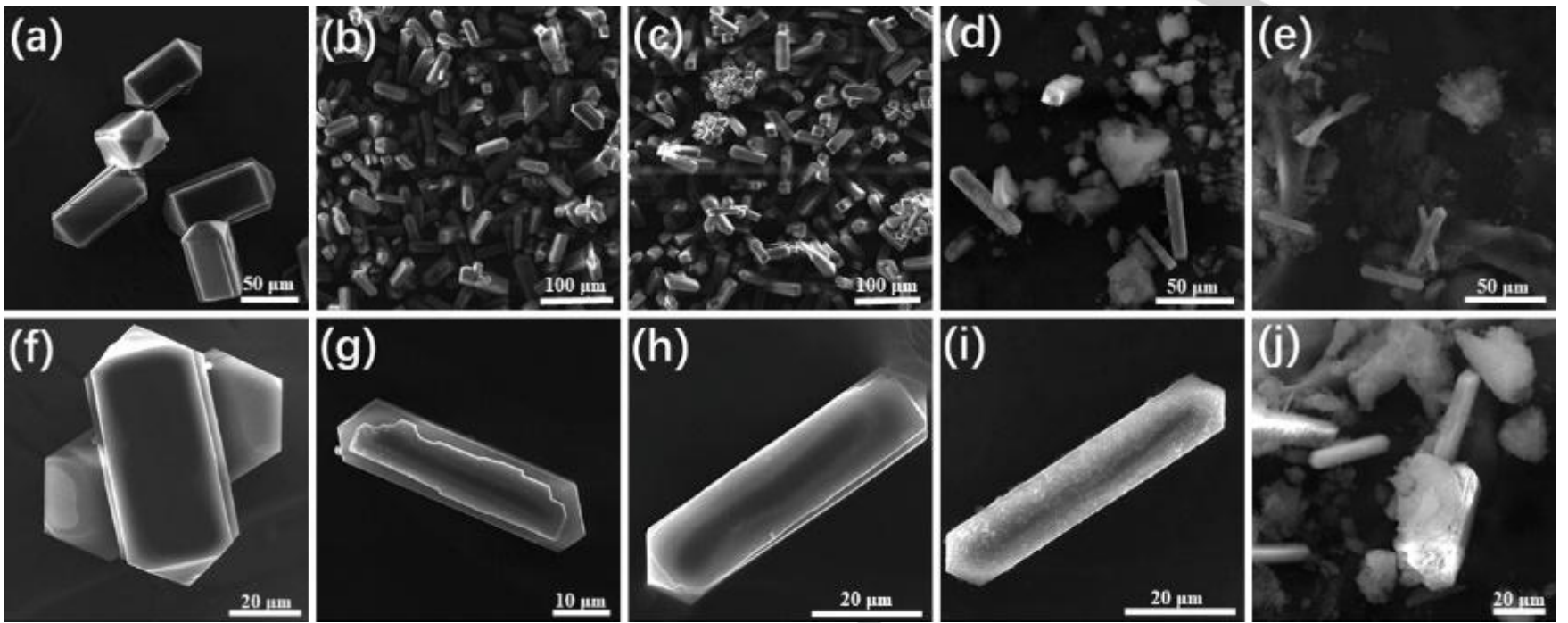

262

263

Figure 2. SEM micrographs of the MFI-type materials synthesized from gels with different Si/Al ratios at $160{ }^{\circ} \mathrm{C}$ for 13 days. Low and high magnification images of FS- $\infty$ (a, f), FS-300 (b, g), FS-150 (c, h), FS-100 (d, i), and FS-50 (e, j)

depends on the $\mathrm{pH}$ of the system. Therefore, $\mathbb{8} 89$ have performed a zeta potential analysis ${ }^{[19]} 280$ evaluate how the $\mathrm{pH}$ influences the surface charzel of fumed silica. The measurements wete 2 performed in the $\mathrm{pH}$ range $1-11$, as ear 3 experiment was repeated ten times. Figure 284 shows the zeta potential plot of the fumed silica 285 a function of the $\mathrm{pH}$ value. The isoelectric point 296 the employed fumed silica, where the surfare 7 charge of silica species is electrically neutral, w2 88 found to be in the $\mathrm{pH}$ range $2.0-2.2$.

The results of zeta potential measurements shea0 light on the crystalization behavior of MFI-type1 zeolite in acidic medium. The zeolite formation 2 under acidic medium is possible solely at pit 3 above the IEP of silica. With the decrease of $\mathrm{tB} A 4$ $\mathrm{pH}$ and approaching the IEP of fumed silica tBe5 zeolite formation is perturbed and even becomed 6 impossible when the surface charge of siliza7 species is inversed to positive, i.e., below tBe8 isoelectric point. In the system under investigatiBa, we have successfully synthesized MFI-type material at $\mathrm{pH}$ equal to 5,3.6 and 2.3; the latter being relatively close to the isoelectric point of fumed silica. The synthesis at a $\mathrm{pH}=2$, which is the IEP of the employed fumed silica, was still possible, but the time required to obtain a highly crystalline product was substantially extended. In the system with $\mathrm{pH}=1.5$, below but yet close to the IEP, only a part of the silica was converted into MFI-type material no matter the fact that the synthesis time was tripled. The last result might look surprising, but there is not a discrepancy in the experimental data. Namely, the surface charge in the IEP is considered neutral in the statistical mean. Close to the IEP there are still negatively charged silica species, which interact with the positively charged $\mathrm{TPA}^{+}$. These interactions, however, are strongly perturbed, which explain the decrease in the crystal growth rate and the partial conversion of silica into the zeolite. Only when the $\mathrm{pH}$ of the gel is substantially below the isoelectric point, and the charge of silica is fully inverted to positive the formation of zeolite is suppressed. 


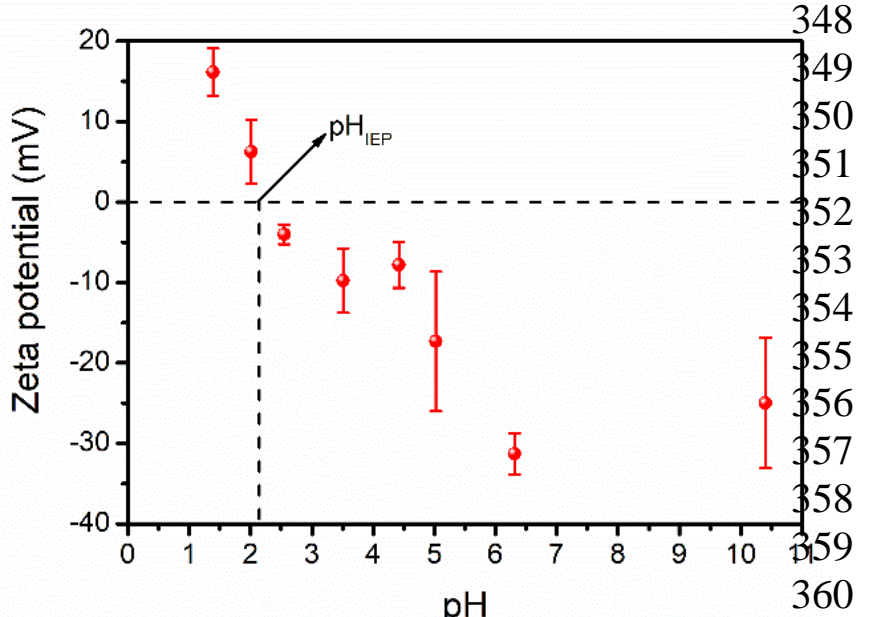

319

312

313

314

315

316

317

318

Figure 3. Zeta potential of fumed silica as a function of $\mathrm{pH}$.

As reported above, the presence of $\mathrm{Al}$ in $\operatorname{th} 63$ initial gel has a negative impact on the zeolist 64 formation under acidic medium. Only when $\mathrm{Si} / 365$ ratio is above 150 , i.e., when a few $\mathrm{Al}$ atoms we 866 introduced in the initial gel, the MFI-type materid7 can be readily obtained. The crystallinity of the8 samples synthesized from the initial systems with $\mathrm{Si} / \mathrm{Al}$ ratio of 100 and 50 was 63 and 33 36,0 respectively (Table 1). We attribute this result 3of 1 the higher IEP of aluminum hydroxide, which is 3 at 2 $\mathrm{pH}=7.7 .^{[20]}$ Thus the positively chargs 43 aluminum species exhibit repulsive interactions $\$ 4$ with the positively charged template. Thus the5 zeolite formation is sensitive to the $\mathrm{Si} / \mathrm{Al}$ ratio 3 nू 6 acidic medium. This result shows that the7 incorporation of transition metals in the zeoliste8 framework under acidic conditions will depeBd 9 strongly on the isoelectric point of meb 0 hydroxide.

The MFI-type materials were subjected to physicochemical characterization using complementary methods to evaluate the impact of the acidic medium on their properties. The crystallinity of materials was already discussed based on X-ray diffraction study. The short-range order was studied by comparing the ${ }^{29} \mathrm{Si}$ MAS NMR spectra of silicalite-1 synthesized in acidic medium $(\mathrm{FS}-\infty)$, and a counterpart synthesized in basic medium (Figure S9). The resonances observed in ${ }^{29} \mathrm{Si}$ MAS NMR correspond quaternary Qn species, with $n=1,2,3$, or 4 stands for the number of another silicon atom direct38 connected to the $\mathrm{Si}$ atom concerned, through 384 oxygen bond $(\mathrm{Si}-\mathrm{O}-\mathrm{Si})$. The two samples display resonances in the $[-107 \mathrm{ppm} ;-120 \mathrm{ppm}]$ corresponding to Q4 species (Figure 4). In contrast to the material synthesized in basic medium (Figure 4b), the FS- $\infty$ sample exhibits well-resolved peaks corresponding to Q4 $(\mathrm{Si}-$ (OSi)4) silicon species, reflecting different crystallographic $\mathrm{T}$ positions in MFI-structure (Figure 4a). The Q4 resonances of the basic medium synthesized silicalite-1 (Figure 4b) are broader because of a less ordered threedimensional $\mathrm{Si}-(\mathrm{OSi}) 4$ network. Also, a broad resonance at $-103 \mathrm{ppm}$ corresponding to $\mathrm{Q} 3$ ( $\mathrm{Si}-$ $(\mathrm{OSi}) 3-\mathrm{OH})$ is observed. This is typical of a discontinuity between $\mathrm{SiO}_{4}$ tetrahedra, leading to the formation of $\mathrm{Si}-\mathrm{OH}$ bonds, and thus defect sites in the zeolite framework. However, no Q3 is observed in the spectrum of FS- $\infty$ (Figure 4a), which is confirmed by the absence of signal enhancement in this region in the ${ }^{29} \mathrm{Si}\{1 \mathrm{H}\} \mathrm{CP}$ MAS spectrum (Figure 4, inset). The last result unambiguously proves a lack of $\mathrm{Si}-\mathrm{OH}$ defects in FS- $\infty$, reinforcing the conclusion of a wellordered 3D structure.

The FS- $\infty$ spectrum contains a broad peak at $125 \mathrm{ppm}$, which is not observed in the reference basic medium synthesized silicalite- 1 . This peak is attributed to the fluoride ions, which have certain mobility between $\mathrm{SiO}_{4} / 2$ tetrahedra. The large signal is thus typical of framework silicon sites that undergo dynamic exchange between 4- and 5coordinated environments, due to fluoride ion mobility. ${ }^{[21]}$ Briefly, the silicalite-1 sample synthesized under acidic conditions exhibits the.

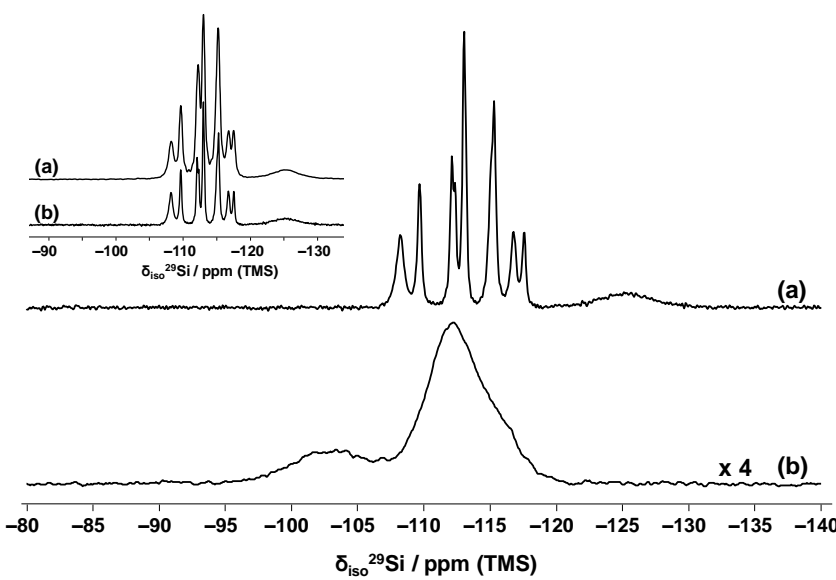

Figure 4. Weight normalized ${ }^{29} \mathrm{Si}$ MAS NMR spectra of as-synthesized silicalite-1 samples synthesized in (a) acidic (FS- $\infty$ ) and (b) basic medium. Inset: (a) ${ }^{29} \mathrm{Si}\{1 \mathrm{H}\}$ CPMAS and (b) ${ }^{29} \mathrm{Si}$ MAS NMR spectra of as synthesized silicalite-1 samples synthesized in acidic (FS- $\infty$ ) medium. 
386 typical high ordering and absence of framewołk6 387 defects characteristic for the synthesis in fluorita? 388 medium

389 The incorporation of $\mathrm{Al}$ in zeolite framewo $\mathbb{R} 9$ 390 was studied by ${ }^{27} \mathrm{Al}$ MAS NMR on sample F $\$ 440$ 391 150. Figure S10 shows the spectra of alst1 392 synthesized and calcined ZSM-5 samplle2 393 synthesized in acidic medium. Both sample 3 394 exhibit aluminum signal in the region of 55 pplm 4 395 corresponding to framework tetrahedral Al sitest5 396 In the case of calcined sample (Figure S10by)6 397 another resonance is observed at $\simeq 0 \mathrm{ppm} 47$ 398 corresponding to extraframework octahedft48 399 aluminum species, which have left the 400 intraframework tetrahedral environment. The 0 401 broadening of this signal is due to a distribution 4ffl $402 \mathrm{Al}^{\mathrm{VI}}$ environment. The fraction of octahedral $\mathrm{AF} 2$ 403 was ca. $10 \%$.

404 The FS series of samples were subjected 454 405 thermal analysis to evaluate template and water 5 406 content (Figure S11). The weight loss bel $\$ 56$ $407300{ }^{\circ} \mathrm{C}$ is attributed to water release, and the ofm7 408 in the temperature range $300-600{ }^{\circ} \mathrm{C}$ to the 8 409 combustion of the TPA (Table 1). Higtlly9 410 crystalline samples show negligible loss beletw0 $411300{ }^{\circ} \mathrm{C}$, which reveals their hydrophobic nature. 41 412 similar weight loss was observed in the high62 413 temperature range corresponding to 4 TPA 3 414 molecules per unit cell. The samples that were 415 fully crystalline (FS-100 and FS-50) show 465 416 higher water content and lower template conte 66 417 Thus, there is a close correlation between th67 418 crystallinity of the samples and the results 468 419 thermal analysis.

420 The porosity and textural characteristics of the 0 421 FS series of samples were determined by nitrog $₫$ 1 $422 \quad\left(\mathrm{~N}_{2}\right)$ adsorption-desorption measurements at $774 \mathbb{1} 2$ 423 (Figure $\mathrm{S} 12$ ). The $\mathrm{N}_{2}$ sorption isotherms of hightly 3 424 crystalline samples (FS- $\infty$, FS-300, and FS-1507) 4 425 displayed the typical type I isother 77,5 426 characteristic of microporous materials. ${ }^{[22]}$ Thes $\$ 26$ 427 samples exhibit a second small uptake with7 428 hysteresis at about $0.1 \quad \mathrm{P} / \mathrm{P}_{0}$. Such additionta8 429 hysteresis has already been reported for silicalitfe- 9 $43011^{[23]}$ The most plausible explanation of this 431 feature is the orthorhombic - monoclinic phat 81 432 transition of the MFI-type framework. ${ }^{[22,24]}$ Th\&2 433 micropore volume of these samples is $0.18 \mathrm{~cm}^{3} \mathrm{~g}^{-1}$, 434 which proves an excellent crystallinity. Lower 435 micropore volume was recorded for FS-100 and 43
FS-50, which is in line with the XRD analysis (Table 1).

The set of the physicochemical analyses shows that the properties of zeolites synthesized in an acidic fluorine-containing medium are similar to their counterparts obtained in a neutral medium using fluorine as a mineralizer.

The set of experimental data shows that it is possible to form a zeolite under acidic medium. The critical factor determining the ability of zeolite to crystallize under acidic conditions is the isoelectric point of silica, i.e., the surface charge of silica species. In the present case, the fumed silica with IEP around two readily transformed into MFI-type material in the $\mathrm{pH}$ range 2-5. Close to the IEP, the zeolite synthesis was still possible, but the crystallization rate slowed down, and only partial transformation of the initial system into zeolite was observed. Using a gel with $\mathrm{pH}$ below the IEP did not yield a zeolitic material since the surface charge of silica was reversed, which led to repulsive interactions with the structure-directing agent.

It should be noted the role of the $\mathrm{F}^{-}$as mineralizer that dissolves silica source and transport the silica species to the structure directing agent. The solubility of silica is limited in most of mineral acids, which make them unappropriate for zeolite synthesis. Thus the HF acid and its derivatives are probably the sole option for zeolite synthesis in acidic medium.

The aluminum incorporation in zeolite framework is limited under acidic conditions, which is a consequence of the high IEP of alumina with respect to silica. Hence the introduction of heteroatoms in zeolite structure will strongly depend on their IEP, i.e., the surface charge of their species in acidic medium.

The present study opens the route to the acidic medium synthesis of zeolites. This pioneering work will have to be further deepened to reach a practical perspective, as the first issues are the incorporation of heteroatoms in the zeolite framework and the decrease of the crystal size. The recycling of fluoride effluent will be necessary to make the process environmentally benign. 
V.V., S.Q. and Q.F. acknowledge the supp 943 from the joint Sino-French internationsol 4 laboratory "Zeolites". V.V. acknowledges thgs5 talent start-up funding provided by QIBEBT. Q\$36 thanks the National Natural Science Foundation 9077 China (21571079, 21621001, 213903938 21571076 and 21571078) for financial support. 539

Keywords: Acidic medium • Crystallization • MFI-type • Zeolif941 542 a) J. Y. Li, A. Corma, J. H. Yu, Chej4 3 Soc. Rev. 2015, 44, 7112-7127; b) 544 Valtchev, L. Tosheva, Chem. Rev. 201345 113, 6734-6760; c) C. Martínez, \$46 Corma, Coord. Chem. Rev. 2011, 25547 1558-1580; d) S. Mintova, M. Jaber, 548 Valtchev, Chem. Soc. Rev. 2015, 44, 720749 7233.

[2] A. Khamkeaw, M. Phisalaphong, 550 Jongsomjit, K. A. Lin, A. C. K. Yip, 552 Hazard. Mater. 2019, 384, 121161.

[3] a) F. Dubray, S. Moldovan, C. Kouvatał J. Grand, C. Aquino, N. Barrier, J. P55 $_{55}$ Gilson, N. Nesterenko, D. Minoux, 556 Mintova, J. Am. Chem. Soc. 2019, 1455 8689-8693; b) M. Smaihi, O. Barida, $5 / 58$ Valtchev, Eur. J. Inorg. Chem. 200359 2003, 4370-4377; c) R. F. Lobo, S. 560 Zones, M. E. Davis, Journal of inclusigb1 phenomena and molecular recognition $\$ \mathrm{j}_{2}$ chemistry 1995, 21, 47-78.

[4] P. Barrett, M. Camblor, A. Corma, 563 Jones, L. Villaescusa, J. Phys. Chem. 585 1998, 102, 4147-4155.

[5] Z. Qin, L. Lakiss, L. Tosheva, J.-P. Gils $\$ 367$ A. Vicente, C. Fernandez, V. Valtche568 Adv. Funct. Mater. 2014, 24, 257-264. 569

[6] R. M. Barrer, Hydrothermal chemistry 5 ff 0 zeolites, Academic press, 1982.

571

[7] R. M. Milton, Molecular sieve science aßg technology: a historical perspective. AGS Publications, Eds. M. L. Occeli \& H. \$74 Robson, 1989, pp. 1-10. 575

[8] D. W. Breck, Zeolite molecular sievesti6 structure, chemistry and use, Wiley, New/7 York, 1974. 578

[9] E. M. Flanigen, R. L. Patton, United Statesp9 Patent, No. 4073865, 1978.
[10] a) J. Guth, H. Kessler, J. Higel, J. Lamblin, J. Patarin, A. Seive, J. Chezeau, R. Wey, ACS Publications, 1989, pp. 176-195; b) J. Guth, H. Kessler, P. Caullet, J. Hazm, A. Merrouche, J. Patarin, in Proceedings from the Ninth International Zeolite Conference, Elsevier, 1993, pp. 215-222; c) J. Guth, H. Kessler, R. Wey, in Studies in Surface Science and Catalysis, Vol. 28, Elsevier, 1986, pp. 121-128.

[11] P. Caullet, J.-L. Paillaud, A. SimonMasseron, M. Soulard, J. Patarin, Comptes Rendus Chimie 2005, 8, 245-266.

[12] B. Louis, L. Kiwi-Minsker, Microporous Mesoporous Mater. 2004, 74, 171-178.

[13] F. Ngoye, L. Lakiss, Z. Qin, S. Laforge, C. Canaff, M. Tarighi, V. Valtchev, K. Thomas, A. Vicente, J. P. Gilson, Y. Pouilloux, C. Fernandez, L. Pinard, $J$ Catal. 2014, 320, 118-126.

V. Eroshenko, R.-C. Regis, M. Soulard, J. Patarin, J. Am. Chem. Soc. 2001, 123, 8129-8130.

[15] a) F. L. Bleken, S. Chavan, U. Olsbye, M. Boltz, F. Ocampo, B. Louis, Applied Catalysis A: General 2012, 447-448, 178185; b) O. Larlus, V. P. Valtchev, Chem. Mater. 2005, 17, 881-886.

[16] C. A. Fyfe, D. H. Brouwer, A. R. Lewis, J.-M. Chezeau, J. Am. Chem. Soc. 2001, 123, 6882-6891.

[17] a) O. B. Ayodele, H. F. Abbas, W. Daud, Energy Conv. Manag. 2014, 88, 11111119; b) C. I. Round, C. D. Williams, K. Latham, C. V. Duke, Chem. Mater. 2001, 13, 468-472.

[18] S. Mintova, V. Valtchev, Microporous Mesoporous Mater. 2002, 55, 171-179.

[19] J. Antonio Alves Júnior, J. Baptista Baldo, New Journal of Glass and Ceramics 2014, 04, 29-37.

[20] K. Gayer, L. Thompson, O. Zajicek, Can. J. Chem. 1958, 36, 1268-1271.

H. Koller, A. Wölker, L. Villaescusa, M. Diaz-Cabanas, S. Valencia, M. Camblor, $J$. Am. Chem. Soc. 1999, 121, 3368-3376.

[22] K. A. Cychosz, R. Guillet-Nicolas, J. Garcia-Martinez, M. Thommes, Chem. Soc. Rev. 2017, 46, 389-414. 
580 [23] a) U. Müller, K. Unger, in Studies in Surface Science and Catalysis, Vol. 39, Elsevier, 1988, pp. 101-108; b) K. Nakai, J. Sonoda, M. Yoshida, M. Hakuman, H. Naono, Adsorption 2007, 13, 351-356.

[24] J. Parra, C. Ania, D. Dubbeldam, T. Vlugt, J. Castillo, P. Merkling, S. Calero, J. Phys. Chem. C 2008, 112, 9976-9979. 
This paper deals with the zeolite synthesis in acidic medium. The isoelectric point of silica source is 596 found to be the critical factor controlling the zeolite formation under acidic conditions. The zeolite 597 